\title{
QUÍMICA E FARMACOLOGIA DE QUIMIOTERÁPICOS ANTINEOPLÁSICOS DERIVADOS DE PLANTAS
}

\author{
Hugo N. Brandão \\ Departamento de Saúde, Universidade Estadual de Feira de Santana, Av. Transnordestina, s/n, 44036-900 Feira de Santana - BA, Brasil \\ Juceni P. David*, Ricardo D. Couto e Jorge A. P. Nascimento \\ Faculdade de Farmácia, Universidade Federal da Bahia, Rua Barão de Geremoabo, s/n, Campus de Ondina, 40170-290 Salvador-BA, Brasil \\ Jorge M. David \\ Instituto de Química, Universidade Federal da Bahia, Rua Barão de Geremoabo, s/n, Campus de Ondina, 40170-290 Salvador-BA, Brasil
}

Recebido em 11/9/09; aceito em 2/2/10; publicado na web em 18/6/10

\begin{abstract}
CHEMISTRY AND PHARMACOLOGY OF ANTINEOPLASIC CHEMOTERAPEUTICAL DERIVATIVES FROM PLANTS. This review demonstrates the importance of plants as sources of molecules used in anticancer therapies. The approach is performed by relating the active molecules to their origins, details, mechanisms of action, structure-activity relationship and chemical characteristics of chemotherapeutical medicines. It was also described the development of anticancer agents from plants by the pharmaceutical industry and the difficulties to release these compounds as a trademark. These include the well known paclitaxel, docetaxel, vincristine, vinblastine, vinorelbine, vindesine, etoposide, teniposide, and other molecules that are undergoing clinical trials.
\end{abstract}

Keywords: plant $a$ ntineoplasics; chemotherapic; cancer.

\section{INTRODUÇÃO}

Substâncias orgânicas originadas de fontes naturais há muito tempo são utilizadas no tratamento de inúmeras enfermidades no ser humano. Grande parte dos medicamentos encontrados no mercado é derivada direta ou indiretamente de vegetais, micro-organismos, organismos marinhos, vertebrados e invertebrados terrestres. ${ }^{1,2}$ Analisando os medicamentos disponibilizados no mercado entre 1981 e 2002, observa-se que $28 \%$ destes possuem princípios ativos isolados de produtos naturais ou semissintéticos, ao passo que $24 \%$ são sintéticos com grupos farmacofóricos baseados em estruturas de produtos naturais. Portanto, mais da metade dos novos medicamentos lançados no referido período são derivados de produtos naturais, mostrando que essa fonte é muito importante nos estudos de desenvolvimento de novos medicamentos. ${ }^{1,3}$

Os vegetais representam as maiores fontes de substâncias ativas que podem ser usadas na terapêutica, devido à grande diversidade estrutural de metabólitos produzidos e, talvez, a fonte mais antiga de medicamentos para o homem. Na busca de novos medicamentos originados de plantas são envolvidos diversos conhecimentos que vão desde aspectos agronômicos, botânicos, químicos, farmacológicos e toxicológicos. ${ }^{4}$

Metodologias recentes cada vez mais modernas de isolamento e identificação de compostos de fontes naturais têm propiciado aumento no número de novas estruturas químicas bioativas para inúmeras indicações terapêuticas. Paralelo a esse progresso, desenvolveram-se métodos de screening biológicos automatizados (High Throughput Screening - HTS) que permitem testar in vitro milhares de substâncias frente a alvos biológicos específicos em curto espaço de tempo.

De acordo com Newman, ${ }^{3}$ medicamentos derivados de produtos naturais são capazes de tratar $87 \%$ das enfermidades humanas categorizadas, incluindo as indicadas como antibacterianas, anticoagulantes, antiparasitárias, imunossupresoras e anticancerígenas. Esta última classe de medicamentos teve 1/3 do mercado em 2002 representado apenas por dois grupos de quimioterápicos derivados de produtos naturais, sendo que os taxanos e derivados da camptotecina representam cerca de U\$ 3 bilhões de dólares. ${ }^{2,5,6}$

*e-mail: juceni@ufba.br
A busca por medicamentos anticancerígenos tem aumentado com vistas a se encontrar tratamentos mais efetivos e seletivos, ou que visem à descoberta de novas estratégias que impeçam o avanço da doença. Baseadas em avanços significativos na biologia do câncer, as pesquisas buscam moléculas que atuem com mecanismos específicos para cada tipo da enfermidade, como inibição da polimerização da tubulina, atuação no DNA, bloqueadores enzimáticos ou de microtúbulos celulares. Moléculas que atuam pelo último mecanismo citado representam grupo das substâncias mais atrativas e promissoras como anticancerígenas de aplicação clínica para grande variedade de câncer, sendo o paclitaxel $\left(\mathrm{Taxol}^{\circledR}\right)$ o principal representante dessa classe. ${ }^{7}$

O câncer é um importante problema de saúde pública para países desenvolvidos e em desenvolvimento, sendo que nestes últimos são diagnosticados 55\% dos 10 milhões de novos casos por ano. ${ }^{8}$ Esta enfermidade é responsável por mais de 7,6 milhões de óbitos por ano, o que representa $13 \%$ de todas as causas de morte do mundo. Os principais tipos de câncer relacionados com mortalidade são de pulmão (1,3 milhões mortes/ano), estômago (aproximadamente 1,0 milhão mortes/ano), fígado (662 mil mortes/ano), cólon (655 mil mortes/ano) e mama (502 mortes/ano). Estimativas sugerem que a mortalidade por câncer continue aumentando, chegando a 9,0 milhões de mortes em 2015 e 11,4 milhões em $2030 .{ }^{9}$

\section{Sobre câncer e seu tratamento}

O câncer é uma enfermidade caracterizada por crescimento desordenado e descontrolado de algumas células e, atualmente, está relacionada ao termo neoplasia maligna. ${ }^{10}$ Pode afetar pessoas de todas as idades, mas o risco para a maioria dos tipos de câncer aumenta com a idade, como demonstrado em estudos que mostram correlações entre números de novos casos de câncer com idade e sexo dos pacientes. ${ }^{11}$

Os diferentes tipos de câncer correspondem aos vários tipos de células do corpo. Por exemplo, existem diversos tipos de câncer de pele porque a pele é formada de mais de um tipo de célula. Se o câncer tem início em tecidos epiteliais como pele ou mucosas ele é denominado carcinoma. Se começa em tecidos conjuntivos como osso, músculo ou cartilagem é chamado de sarcoma. Linfoma é o 
nome genérico usado para designar todo tipo de câncer do sistema linfático e leucemia refere-se ao câncer nas células jovens sanguíneas que se acumulam na medula óssea. ${ }^{12}$

Devido à relativa semelhança entre células malignas e normais do corpo, o grande desafio para o tratamento de cânceres é a distinção entre essas células. $\mathrm{O}$ tratamento da maioria dos casos de câncer consiste na combinação de diferentes técnicas como, por exemplo, cirurgia e quimioterapia. ${ }^{13}$ Esta última baseia-se na busca por destruição das células neoplásicas, que têm como característica o fato de se dividirem muito mais rápido que a maioria das células normais. Contudo, podem ocorrer efeitos secundários importantes naquelas células normais de crescimento rápido, como as gastrointestinais, capilares e as do sistema imunológico, causando diarréia, náuseas, vômitos, alopecia e maior susceptibilidade às infecções. ${ }^{10}$

Nos últimos 50 anos, a pesquisa de novos fármacos anticancerígenos introduziu na terapêutica cerca de 70 medicamentos. Entre 1955 e 1975, a triagem de novos anticancerígenos foi realizada somente através de modelos experimentais de leucemias murínicas (L1210 e P388). Após 1975, a triagem passou a ser realizada em dois estágios. No primeiro estágio, esses eram selecionados através de modelo de leucemia murínica (P388) e no segundo, passavam por modelos utilizando animais imunodeficientes, com implante de células tumorais humanas. Durante esse período foram avaliadas cerca de $600 \mathrm{mil}$ substâncias que resultaram na maioria dos fármacos que hoje são utilizadas na quimioterapia anticâncer. ${ }^{14}$

Os agentes hoje conhecidos com ação sobre o câncer podem ser classificados em dois grupos. O primeiro é constituído por aqueles que inibem a iniciação do processo carcinogênico e o segundo, por aqueles que inibem a proliferação celular durante as fases de promoção e progressão do câncer. ${ }^{15}$ No primeiro grupo pode ser citado o exemplo do consumo regular de chá verde, Camellia sinensis, no Oriente. Observa-se que nessa região a incidência de câncer de cólon e mama é muito mais baixa comparada com dados do Ocidente, podendo ser justificado pelos flavonoides e outros compostos fenólicos presentes no chá verde, especialmente a 3-galato-epigalocatequina, que possuem atividade comprovada em diversos sistemas fisiológi$\cos .{ }^{16}$ Enquanto que os agentes supressores de câncer são os mais procurados para o desenvolvimento de novos fármacos, pois atuam após a instalação da doença.

\section{Anticancerígenos derivados de plantas}

A descoberta de novos anticancerígenos de origem vegetal tem incentivado as pesquisas nessa área. Um dos exemplos mais importantes é o da Catharanthus roseus (L.) G. Don, conhecida também como Vinca, que é utilizada pela população de Madagascar no tratamento de diabetes. Durante os testes de atividade hipoglicemiante, os extratos dessa espécie produziram granulocitopenia em consequência da supressão da medula óssea dos animais, sugerindo avaliação em modelos de leucemias e linfomas. A confirmação da atividade nesses modelos levou ao isolamento dos alcaloides vimblastina (1) e vincristina (2) que, atualmente, são de grande utilidade no tratamento de linfoma de Hodgkin, sarcoma de Kaposi, câncer de ovário e testículos e leucemia linfoblástica aguda infantil. Outra descoberta importante na área de câncer foi a das substâncias presentes em espécies do gênero Podophyllum, tais como $P$. peltatum e $P$. emodii, utilizadas pelas populações nativas da América e da Ásia no tratamento do câncer de pele e verrugas. A partir da podofilotoxina (3), uma lignana ariltetralínica, foram obtidos o etoposídeo (4) e o teniposídeo (5), cujos estudos experimentais permitiram a introdução desses na terapia do câncer. Estas descobertas encorajaram o Instituto Nacional do Câncer dos Estados Unidos (NCI) a realizar o programa de screening, para agentes anticancerígenos, com vegetais. Entre 1960 e 1982 foram avaliadas 35.000 amostras vegetais. O resultado mais importante foi a descoberta do paclitaxel (6), isolado da casca do teixo (Taxus baccata L. e Taxus brevifolia Nutt.) em 1971. Estudos clínicos revelaram que essa substância era capaz de regredir o câncer de mama e de ovário, resistentes à terapia tradicional. ${ }^{14,17}$

As estruturas químicas de algumas substâncias com atividade anticancerígena, derivadas direta ou indiretamente de vegetais, estão representadas na Figura 1.

\section{Interações dos anticancerígenos com DNA topoisomerases}

Anticancerígenos podem atuar diretamente no DNA das células, ou indiretamente por inibição de funções metabólicas do DNA. Exemplo de tal fato é a ação sobre a enzima DNA topoisomerase I, também conhecida como TOP1, que promove a quebra de uma das fitas de DNA e permite o giro da fita quebrada sobre a fita intacta, de forma a reduzir a tensão torcional da molécula. Algumas substâncias, como as camptotecinas, inibem a religação do DNA depois da quebra mediada pela TOP1 (Figura 2).${ }^{18} \mathrm{~A}$ enzima TOP1 pode ser ainda subdividida em tipo IA e tipo IB. O Tipo IA rompe o DNA por formação de ligação covalente 5'-fosfotirosil e consequente relaxamento da tensão por passagem de uma fita sobre a outra e, a tipo IB forma uma ligação covalente com o final da fita 3' e relaxa o DNA por rotação controlada. ${ }^{19}$

A tensão do DNA é causada pela replicação, transcrição e remodelagem da cromatina (a). Uma das fitas é quebrada pela TOP1 e favorece a formação do ponto de giro que habilita a rotação da fita intacta pela fita quebrada (b). Assim, é possível visualizar (c) a expansão do relaxamento do DNA pelo complexo de clivagem TOP1 (TOP1cc), que pode ser estabilizado por fármacos como as camptotecinas. ${ }^{19}$

Inibidores de topoisomerases agem principalmente na etapa intermediária da clivagem, e a fita permanece clivada por períodos de tempo praticamente indetectáveis. Grandes quantidades de TOP1cc favorecem modificações no DNA e apoptose. Durante a religação do TOP1cc ocorre ataque nucleofílico na ligação fosfodiéster-DNAtirosil pelo final da fita de DNA livre, 5'-hidroxil-DNA, sendo crucial o perfeito alinhamento destes.

A camptotecina (7) é um alcaloide extraído e isolado de uma árvore ornamental chinesa, Camptotheca acuminata Decne. (Cornaceae), que deu origem aos conhecidos irinotecan $(\mathbf{8})$ e topotecan (9) que atuam inibindo a enzima topoisomerase I. ${ }^{17}$

Esta classe de anticancerígenos teve início complicado na terapêutica, pois apesar de apresentar resultados promissores em estudos pré-clínicos realizados em 1970, essas substâncias possuíam baixa atividade anticancerígena em ensaios clínicos preliminares e ainda apresentavam toxicidade para os rins. Sua ineficiência in vivo foi atribuída à instabilidade do anel $\alpha$-hidroxi- $\delta$-lactônico em $\mathrm{pH}$ neutro (10). Ao chegarem à urina, com $\mathrm{pH}$ ácido, a molécula ativa era reestruturada causando danos renais tubulares. Somente em 1996, um análogo da camptotecina, o irinotecan, recebeu o aval do Food and Drug Administration (FDA) para o tratamento de câncer de cólon, sendo mais tarde usado também para câncer de pulmão e ovário. ${ }^{20}$

Esses compostos são farmacologicamente únicos por várias razões. Primeiro, devido à TOP1 ser o único alvo, tal como verificado em células que se tornavam resistentes à camptotecina pela retirada do gene específico de TOP1. Segundo, a mudança da estereoquímica da camptotecina por inversão do centro quiral em C20 (o equivalente sintético corresponde à 20-R), torna a molécula completamente inativa. $\mathrm{O}$ terceiro motivo deve-se ao fato da camptotecina conseguir penetrar nas células dos vertebrados e alcançar a TOP1 em minutos após a exposição, sendo reversível com a retirada da mesma. Por último, são detectadas concentrações micromolares do fármaco 

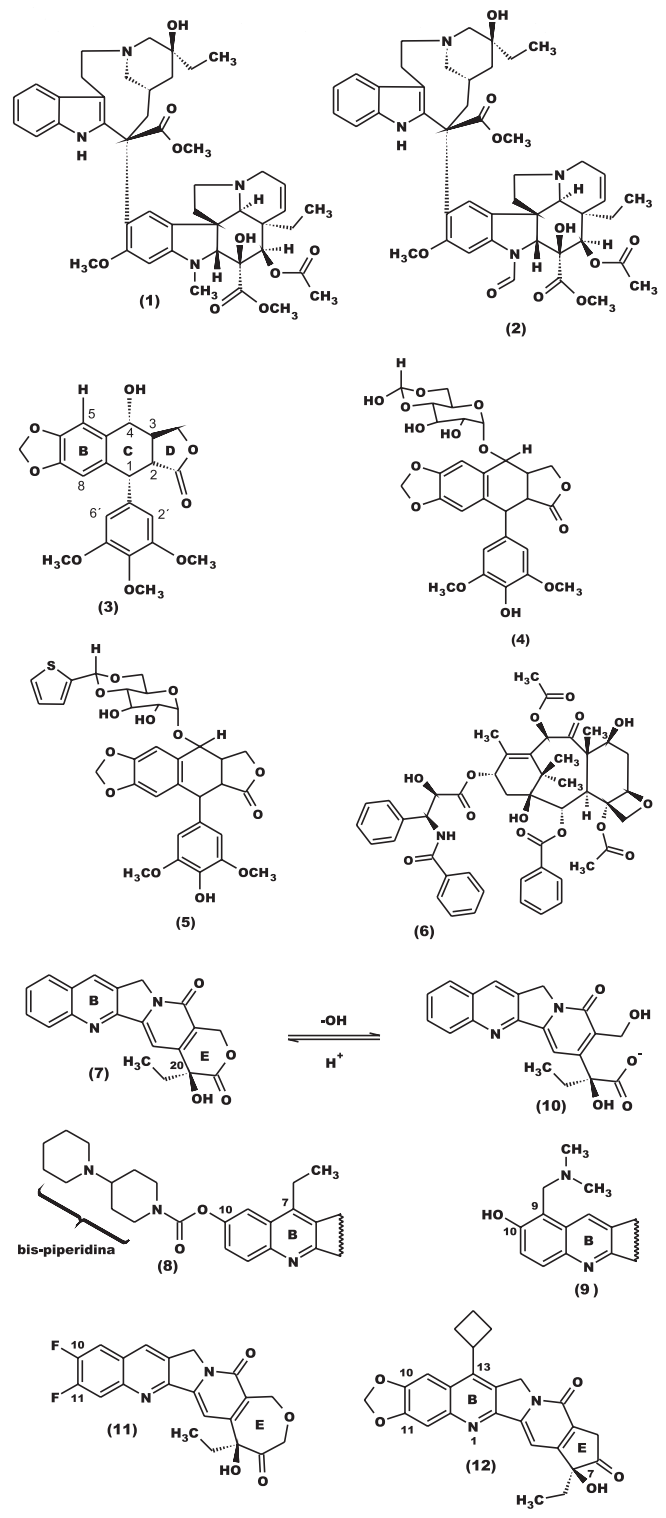

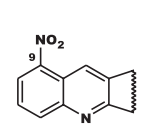

(13)<smiles>Cc1c(F)cc2nc3c(c4c2c1CCC4N)CC3</smiles>

(14)
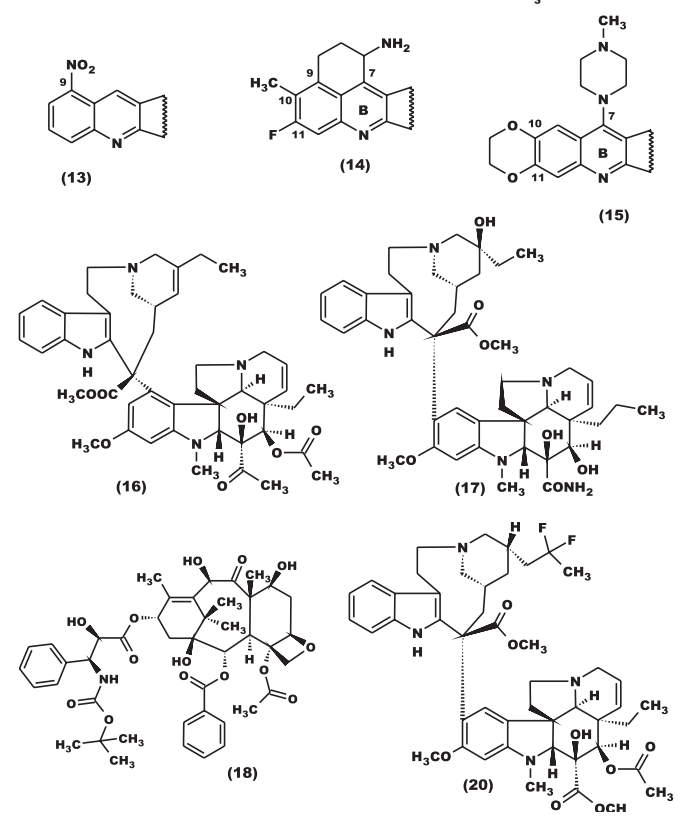

Figura 1. Estruturas químicas de substâncias com atividade anticancerígena derivadas de plantas

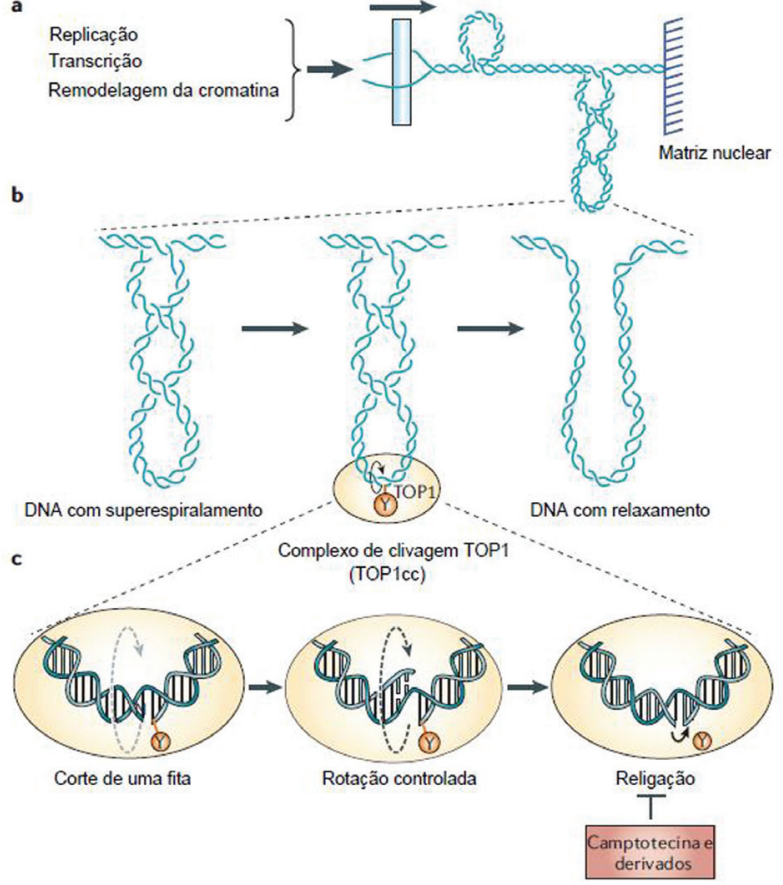

Figura 2. Ação da camptotecina e seus derivados sobre o DNA. Adaptada da ref. 19

ligado a TOP1cc, devido à baixa afinidade desses componentes pelo complexo de clivagem, sugerindo a seletividade e potência favoráveis dessa classe de anticancerígenos. ${ }^{19}$

Campotecina e seus derivados apresentam algumas limitações como efeitos colaterais, leucopenia principalmente, o que limita a dose e a eficácia dos mesmos. Irinotecan produz sérios efeitos colaterais e requer monitoramento de uso. A toxicidade é dose dependente e quase sempre são observados quadros de neutropenia e diarréia severa ${ }^{21}$ que pode ser atribuída ao grupamento bis-piperidina, responável pela maior solubilidade deste em água. O anel "E" $\alpha$-hidroxi- $\delta$-lactônico das camptotecinas é facilmente convertido em carboxilato que, como já citado, é inativo. Entretanto, duas modificações no referido anel foram feitas para contornar esse problema. A adição de um grupo metileno como no diflomotecan (11) termina por estabilizar e manter a inibição à TOP1. Diflomotecan está em fase II de testes clínicos e já mostra toxicidade dose dependente que pode causar mielossupressão. ${ }^{22}$

Outra maneira de estabilização do anel E é através da retirada do grupo lactônico, que bloqueia completamente a abertura do anel, assim como nos derivados cetônicos que também mantêm a alta atividade anti-TOP1. O derivado ciclobutano metilenodióxi, S39625 (12) está em fase pré-clínica avançada de desenvolvimento, ${ }^{19,23,24} \mathrm{com}$ resultados mais potentes que a camptotecina em testes com algumas linhagens de células cancerígenas. Outros derivados da camptotecina (13-15) são mostrados na Tabela 1.

A enzima DNA Topoisomerase II induz a quebra das duas fitas do DNA, reduzindo a tensão torcional no DNA durante a replicação e condensação dos cromossomos nos núcleos durante a divisão da célula. A quebra é momentânea e o reparo do DNA é feito pela mesma TOP2. A função de religação da TOP2 pode ser bloqueada por inibidores dessa enzima e, como consequência, o período em que as duas fitas permanecem quebradas é mais longo e geralmente leva as células a ativarem a via da apoptose. ${ }^{37,38}$ Exemplos de inibidores da TOP2 são etoposídeo e teniposídeo. ${ }^{17}$

Existem duas formas da TOP2, $\alpha$ e $\beta$, que são muito similares mas geneticamente distintas. TOP $2 \alpha$ é expressa em células proliferativas 
Tabela 1. Camptotecinas em uso clínico

\begin{tabular}{lccc}
\hline Derivado da camptotecina & Status & Observações & Indicações \\
\hline Hidrocloreto de irinotecan (Camptosar) & Aprovado pelo FDA (Pfizer) & Infusão intravenosa (solúvel em água) & Câncer colo-retal metastático $^{20,25,26}$ \\
Hidrocloreto de topotecan (Hycamtim) & Aprovado pelo FDA (GlaxoS- & Infusão intravenosa (solúvel em água) & Câncer ovariano metastático ${ }^{27,28}$ \\
Rubitecan (13) (Orathecin) & mithKline) & Administração oral & Câncer pancreático $^{29,30}$ \\
Mesilato de exatecan (14) & Fase II/III (SuperGen) & Infusão intravenosa & Vários carcinomas $^{31-34}$ \\
Lurtotecan (15) & Fase II (Daiichi) & Infusão intravenosa lipossomal & Carcinomas ovarianos $^{35}$ e outros $^{34,36}$ \\
\hline
\end{tabular}

no final da fase $S$, com pico de concentração entre as fases $G_{2}$ e $M$, mas não presente na fase $G_{0}$ que representa células não proliferativas. TOP2 $\beta$ é continuamente expressa durante todo o ciclo celular, inclusive na $\mathrm{G}_{0} \cdot{ }^{39}$

O etoposídeo (4-demetil-7-[4,6-O-etilideno $\beta$-D-glicopiranosil epipodofilotoxina]) e o teniposídeo (4-demetil-7-[4,6-O-tenilideno$\beta$-D-glicopiranosil epipodofilotoxina]) são derivados semissintéticos da podofilotoxina. Estes foram desenvolvidos pela Sandoz em 1970, na tentativa de preparar derivados dessa lignana que não possuíssem efeito tóxico gastro-intestinal. Nos 15 anos seguintes, o etoposídeo e o teniposídeo foram introduzidos no tratamento clínico e estes fármacos têm tido uma participação muito importante no tratamento quimioterápico do câncer.

A configuração 1,2-cis-2,3-trans é essencial para atividade biológica e a estereoquímica de C-4 é menos importante visto que a podofilotoxina e a epipodofilotoxina são facilmente interconvertidas. Entretanto, na síntese do etoposídeo e teniposídeo, a reação de glicosilação em C-4 fornece exclusivamente C-4 $\beta$, independente da configuração antes da semissíntese. ${ }^{40}$

Os derivados semissintéticos da podofilotoxina induzem o bloqueio pré-mitótico no final da fase $S$ ou no início da fase $G_{2}$, devido à ligação destes com a topoisomerase II, inibindo que essa enzima complete sua função e repare as duas fitas de DNA que foram previamente quebradas.

As modificações essencias que convertem a podofilotoxina, uma entidade que interage com a tubulina e bloqueia mitose, em outra estrutura que interrompa o ciclo celular na fase $\mathrm{G}_{2}$ por interação com a TOP2, incluem demetilação no C-4', epimerização e glicosilação em C-4 e acetalização dos grupos hidroxil nas posições 4 e 6 das glicopiranoses..$^{40,41}$

Etoposídeo comumente causa supressão de medula óssea, náusea, vômitos e alopecia e em doses muito altas pode causar hepatotoxicidade, febre e ardor. Reações de hipersensibilidade, incluindo alterações motoras nos sistemas pulmonar e gastrointestinal, também podem ocorrer, tendo causa provável a presença do emulsificador Tween 80. Tais reações podem ser tratadas com baixa taxa de infusão ou com medicamentos sintomáticos, como anti-histamínicos e antiinflamatórios. Fosfato de etoposídeo, pró-fármaco hidrossolúvel, é uma boa alternativa, visto que é rapidamente convertido a etoposídeo por fosfatases endógenas. ${ }^{42} \mathrm{O}$ efeito adverso mais sério induzido pelo etoposídeo é o possível desenvolvimento de leucemia mieloide aguda, com diferenças de incidência de acordo com a indicação do tratamento. ${ }^{43}$

Aproximadamente 1/3 do etoposídeo administrado intravenosamente é excretado pela urina. Poucas interações medicamentosas são relatadas para este, como o aumento do clearance renal por uso concomitante com prednisona. O uso de medicamentos por via oral facilita tratamentos de longa duração, mas para o etoposídeo a biodisponibilidade por essa via varia entre 40 e $80 \%$. As indicações desse incluem câncer de pulmão, linfomas não-Hodgkin, sarcoma de Kaposi, sarcomas de tecidos moles e neuroblastoma. ${ }^{43}$

O teniposídeo, como já mostrado, é análogo do etoposídeo e teve seu uso aprovado nos Estados Unidos 10 anos após o etoposídeo, em 1993. Usado principalmente no tratamento de linfomas infantis e leucemias, além de cânceres no sistema nervoso central (SNC), o mecanismo de ação é similar ao do etoposídeo por interação com a topoisomerase II, com consequente formação de complexos que inibem a religação das duas fitas de DNA partidas. Reações de hipersensiblidade são mais comuns. O teniposídeo in vitro é dez vezes mais potente que o etoposídeo, provavelmente por poder ser absorvido mais facilmente pelas células, porém in vivo possuem habilidades semelhantes de inibição da TOP2. Além disso, o teniposídeo possui menor clearance renal, cerca de $10 \%$, e maior afinidade por proteínas plasmáticas, 99\%. Alguns anticonvulsivantes aumentam a depuração desse fármaco, provavelmente pelo aumento do metabolismo hepático. Além das indicações terapêuticas descritas anteriormente, o teniposídeo é também indicado para casos de leucemia linfoblástica aguda infantil, e para os adultos em casos de câncer de bexiga, sarcoma de Kaposi, leucemias e linfomas. ${ }^{44}$

\section{Interações com microtúbulos}

Outras substâncias extraídas de plantas com atividade contra o câncer exercem seus efeitos interagindo com proteínas e microtúbulos. Estes últimos são longos filamentos em forma de tubo formado por polímeros de proteínas que são componentes chaves do citoesqueleto e essenciais em células eucarióticas. São essenciais para o desenvolvimento e a forma das células, transportes de componentes, sinalização celular e no processo de mitose em que os cromossomos duplicados de uma célula são separados em dois idênticos antes da clivagem em duas células filhas. ${ }^{45}$ Esse processo requer o equilíbrio dinâmico entre organização e desorganização dos microtúbulos, portanto qualquer distúrbio nesse equilíbrio pode causar a interrupção da mitose e consequente morte da célula. ${ }^{18}$

Microtúbulos são formados por heterodímeros de $\alpha$-tubulina e $\beta$-tubulina arranjados em forma de filamentos delgados (Figura 3). A função desses microtúbulos na mitose e divisão celular faz dos mesmos importantes alvos para busca de agentes anticancerígenos. ${ }^{46,47}$ Entre os anticancerígenos que atuam por tal mecanismo, podem ser citados os alacaloides da Vinca, os taxanos e a colchicina (Tabela 2).

Antimitóticos que atuam em microtúbulos podem ser classificados em dois grupos. O primeiro refere-se aos desestabilizadores de microtúbulos, inibindo a polimerização dos mesmos por ligação à tubulina e, o segundo grupo é conhecido como estabilizadores de microtúbulos, que estimulam a polimerização e inibem a despolimerização. Portanto, a ação desses anticancerígenos suprime a dinâmica dos microtúbulos, o que resulta em lentidão ou bloqueio da mitose na transição da metáfase para anáfase e indução da apoptose. ${ }^{45}$

Os alcaloides da Vinca atuam ligando-se às $\beta$-tubulinas inibindo a polimerização dos microtúbulos. Os representantes naturais, vimblastina e vincristina, dessa classe foram isolados das folhas da espécie Catharanthus roseus (L.) G. Don. (Apocynaceae), antigamente chamada de Vinca rosea L. e popularmente conhecida como Vinca.

No final dos anos 50, foi descoberta a propriedade antimitótica desses alcaloides e, a vimblastina e vincristina foram aprovadas como agentes anticancerígenos, pelo FDA em 1963 e 1965, respectivamen- 
Tabela 2. Fármacos antimitóticos que interagem com tubulina

\begin{tabular}{|c|c|c|c|}
\hline Classe & Fármaco & Status & Indicações \\
\hline \multirow[t]{4}{*}{ Alcaloides da vinca } & Vimblastina (Velban) & Aprovado pelo FDA (Eli Lilly) & Doença de Hodgkins, ${ }^{48,49}$ câncer testicular ${ }^{50,51}$ \\
\hline & Vincristina (Oncovin) & Aprovado pelo FDA (Eli Lilly) & Leucemia,,$^{52,53}$ linfomas $^{54,55}$ \\
\hline & Vinorelbina (16) (Navelbina) & Aprovado pelo FDA (Asta Médica) & Tumores sólidos, ${ }^{56,57}$ câncer de pulmão ${ }^{56,58}$ \\
\hline & Vindesina (17) (Eldisina) & Aprovado pelo FDA (Eli Lilly) & $\begin{array}{l}\text { Leucemia linfoblástica aguda infantil },^{59,60} \text { câncer } \\
\text { de pulmão } \\
61,62\end{array}$ \\
\hline \multirow[t]{2}{*}{ Taxanos } & Paclitaxel (Taxol) & Aprovado pelo FDA (Bristol-Myers) & Câncer de pulmão, ${ }^{63,64}$ ovário ${ }^{64,65}$ e mama ${ }^{66,67}$ \\
\hline & Docetaxel (18) (Taxotere) & Aprovado pelo FDA (Sanofi-Aventis) & Câncer de pulmão ${ }^{68,69}$ e próstata ${ }^{70,71}$ \\
\hline Colchicinas & $\begin{array}{l}\text { Colchicina }(\mathbf{1 9}) \\
\text { (Colcitrat) }\end{array}$ & $\begin{array}{c}\text { Ainda não aprovado como anticancerígeno por } \\
\text { apresentar elevada toxicidade }\end{array}$ & Doenças não neoplásicas (gota) ${ }^{45,72}$ \\
\hline
\end{tabular}

te. Desde então, vários análogos semissintéticos têm sido pesquisados, alguns com resultados muito favoráveis, como vinorelbina, vindesina e vinflunina (20). ${ }^{60}$

Vimblastina liga-se às $\beta$-unidades de tubulinas em sítios específicos para tais alcaloides e a ligação é rápida e reversível, induzindo mudanças conformacionais na tubulina e dificultando a associação com outras moléculas iguais. A ligação também pode ser feita diretamente aos microtúbulos pela extremidade terminal positiva, sendo que aproximadamente duas moléculas de vimblastina em cada unidade já são capazes de desestabilizar 50\% dos microtúbulos, sem necessariamente causar a despolimerização (Figura 3a). ${ }^{45}$
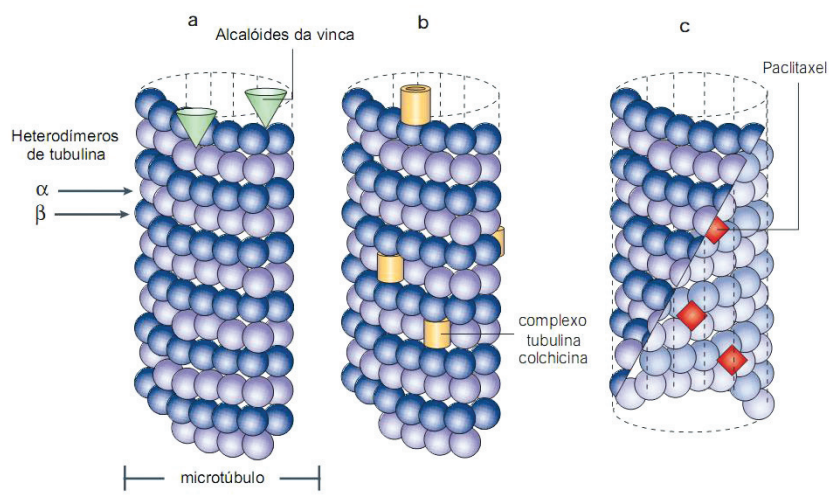

Figura 3. Ligação de fármacos antimitóticos em diferentes locais dos microtúbulos. Adaptada da ref. 45

Os principais efeitos colaterais observados são neuropatias periféricas e mielossupressão reversível. As causas da neurotoxicidade ainda não são muito claras, mas acredita-se que estão relacionadas com os efeitos nos microtúbulos, que são componentes chaves para os neurônios. ${ }^{73}$

Na tentativa de síntese da vimblastina, observou-se que o atropoisômero desta substância não apresentava os mesmos efeitos biológicos esperados para o esqueleto natural e que esse isômero não poderia ser considerado um pró-fármaco da vimblastina, visto que ele precisaria de temperatura de $100{ }^{\circ} \mathrm{C}$ para sua interconversão. ${ }^{74}$ Portanto, evidencia-se a necessidade do anel piperidínico na conformação em cadeira ( 21 e seu atropoisômero $\mathbf{2 2}$ ) para atividade anticancerígena da vimblastina (Figura 4). ${ }^{75}$

Outro alcaloide natural isolado da $C$. roseus com atividade antimitótica pronunciada é a vincristina que, assim como a vimblastina, ocorre em quantidades diminutas no vegetal $\left(2,5 \times 10^{-4} \%\right.$ do peso seco das folhas) e apesar de possuírem características químicas bem semelhantes, apresentam propriedades antitumorais e toxicidades diferenciadas. A estrutura molecular de ambas é formada por núcleos diméricos e assimétricos compostos por uma unidade di-hidroindólica, vindolina, conectada por ligação
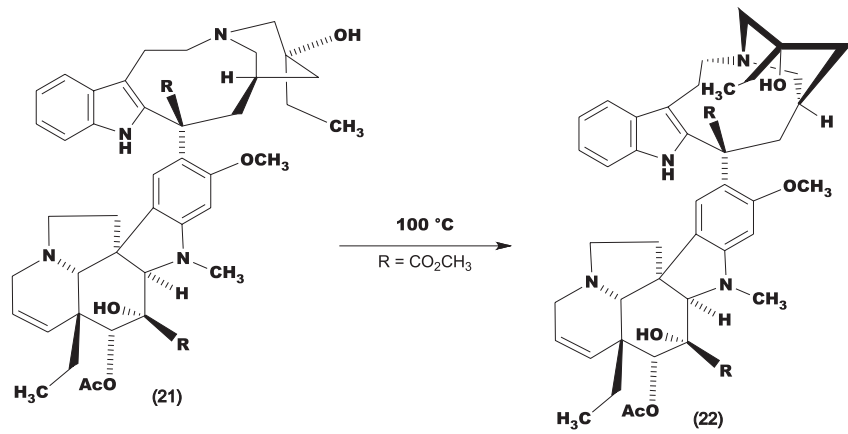

Figura 4. Vimblastina com anel piperidínico em conformação cadeira (21) e seu atropoisômero em cadeira invertida (22)

C-C em uma unidade indólica, catarantina. ${ }^{73} \mathrm{~A}$ pequena diferença estrutural é observada no N-substituinte da unidade di-hidroindólica. A vincristina é usada em terapias combinadas para tratar leucemias infantis e linfomas. A neurotoxicidade continua sendo o principal efeito colateral observado pelo uso clínico da vincristina e a neutropenia associada aos alcaloides da vinca corresponde à toxicidade dose limitante. ${ }^{60}$

Na tentativa de melhor aproveitar os benefícios da C. roseus, a espécie passou por processos biotecnológicos referentes ao metabolismo secundário e, além disso, alguns derivados semissintéticos dos alcaloides ativos surgiram no mercado com o propósito de apresentar maior atividade terapêutica e menos efeitos tóxicos relacionados. Assim, a vinorelbina ou nor-5' -anidrovimblastina (Navelbina ${ }^{\circledR}$ ), um dos derivados alcaloídicos semissintéticos da vinca, possui largo espectro de atividades antitumorais, sendo especialmente ativo no câncer de mama e carcinoma de pulmão de não-pequenas-células. ${ }^{56}$ Comparado com os outros alcaloides da vinca, vinorelbina se mostra mais ativo e menos neurotóxico. ${ }^{76}$ Trata-se de um composto altamente lipofílico que é rapidamente distribuído para tecidos periféricos do corpo. ${ }^{58}$

A vinorelbina é comercializada na forma para administração endovenosa, mas em alguns países é vendida para uso oral. ${ }^{77} \mathrm{Na}$ formulação oral, a vinorelbina é absorvida rapidamente, entre 1:30 a $3 \mathrm{~h}$, com meia-vida de $4 \mathrm{~h}$. Alimentos não interferem na sua farmacocinética. Portanto, apresenta grande vantagem de conveniência e facilidade de administração ao paciente. ${ }^{78}$

Vindesina, ou sulfato de 4-desacetilvimblastinamida (Eldisina ${ }^{\circledR}$ ), é também um derivado semissintético da vimblastina. É relatado como ativo em câncer de mama, melanoma, adenocarcinoma de pulmão e malignidades hematológicas, especialmente naquelas resistentes à vincristina. Essa interrompe a mitose de forma dose-dependente e reversível com a retirada da mesma. ${ }^{79}$

Desde a descoberta da eficácia terapêutica dos alcaloides antimitóticos da vinca (16-19), umas das principais classes de quimioterápicos no câncer, centenas de derivados são produzidos e 
avaliados quanto às atividades biológicas. Um dos mais promissores refere-se ao 20'-20'-difluor-3'-4'-di-hidrovinorelbina, conhecido como vinflunina, que se encontra em ensaios clínicos fase III para tratamentos de câncer de bexiga, com resultados bastante promissores. ${ }^{80}$ A afinidade da vinflunina, comparada com a dos outros alcaloides da vinca, pela tubulina é menor, porém isso não representa menor atividade, pois a força da ligação com a tubulina não é um pré-requisito para eficácia antitumoral, mas está relacionada com o efeito neurotóxico. Isso sugere o motivo da menor neurotoxicidade desse componente. Outra diferença importante é que a vinflunina é um fraco substrato para a glicoproteína-P (P-gp), portanto com menor tendência de induzir resistência. ${ }^{81}$

Entre os principais representantes da classe dos estabilizadores de microtúbulos estão os taxanos, paclitaxel e derivados, que agem pelo mecanismo de estabilizarem microtúbulos e inibirem a despolimerização dos mesmos, causando a morte celular. Estes compostos se ligam fracamente às tubulinas livres, mas com bastante afinidade às que já fazem parte do microtúbulo, nas $\beta$-unidades da superfície interna (Figura 3c). ${ }^{45}$

O primeiro representante dessa classe a receber a aprovação do FDA foi o paclitaxel $\left(\right.$ Taxol $^{\circledR}$ ) em 1992, seguido de seu derivado semissintético docetaxel (Taxotere ${ }^{\circledR}$ ) em 1996. O paclitaxel é um diterpeno complexo da família dos taxanos que foi extraído em 1962 a partir de extratos de casca da árvore conhecida como yem, Taxus brevifolia Nutt. (Taxaceae). ${ }^{7}$ Esse mostrou excelente atividade anticancerígena in vitro e em 1977 começaram os testes pré-clínicos pelo Instituto Nacional do Câncer dos Estados Unidos (NCI).

As propriedades estabilizadoras de microtúbulos do paclitaxel foram descobertas em 1979 por pesquisadores do Albert Einstein Medical College, o que representava um mecanismo de ação nunca observado para nenhuma outra substância. ${ }^{82}$ Uma vez que essa substância teria que ser extraída de espécies que levam décadas para crescer e é produzida em quantidades muito baixas (0,01-0,03\%), a introdução dessa na terapêutica teve que esperar pelo desenvolvimento da síntese química, de extrema complexidade, e pela descoberta de precursores obtidos de fontes renováveis. Tal fato justifica o longo período de tempo entre a descoberta do paclitaxel e seu lançamento no mercado. Para ilustrar, 4 mil árvores foram sacrificadas para render $360 \mathrm{~g}$ de taxol na realização dos testes clínicos e, na década de 90, 38 mil árvores foram utilizadas para fornecer $25 \mathrm{~kg}$ de paclitaxel para tratar cerca de 12 mil pacientes. Obviamente é impossível manter essa fonte natural de obtenção. Isso só foi possível devido à possibilidade da via semissintética. ${ }^{17} \mathrm{O}$ problema foi contornado quando Potier e colaboradores identificaram a presença, e em grande quantidade, da 10-desacetilbaccatina III (23), conhecida como 10-DAB, nas folhas de outra espécie do gênero, popularmente chamada de yem europeia, Taxus baccata. Tal molécula pode ser convertida em paclitaxel e em seu análogo mais potente, o docetaxel (Taxotere $\left.{ }^{\circledR}\right),{ }^{83}$ como observado na Figura 5. A utilização do cloreto de trimetilsilila (TMSCI) efetua a proteção seletiva das posições C-7 e C-10 da 10-DAB, seguida da acetilação da posição C-10 por anidrido acético. A introdução da cadeia lateral em C-13 é feita por utilização da $\beta$-lactama-N-benzoilada em presença da base hexametildissililamideto de potássio (KHMDS). Após a desproteção dos grupos sililas utilizando ácido fluorídrico em piridina, obtêm-se o paclitaxel. ${ }^{82}$

Outro entrave para o emprego do taxol foi a solubilidade, que acabou por ser contornada com a formulação em emulsão lipídica, porém com aumento do número de pacientes com hipersensibilidade ao tratamento ${ }^{84}$ Rodrigues e colaboradores ${ }^{85}$ compararam a toxicidade da emulsão lipídica do paclitaxel comercial (cremophor) com a nova forma de apresentação do paclitaxel em microemulsões de colesterol, chamada de LDE, comprovando que o oleato de paclitaxel-LDE é tão estável quanto o comercial, porém com menos efeitos tóxicos observados.
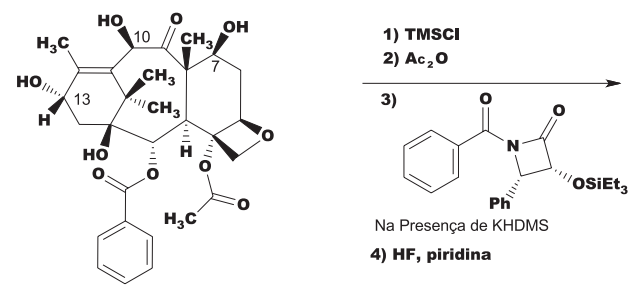

(23)
Figura 5. Semissíntese do paclitaxel a partir da 10-desacetilbaccatina III (10-DAB). Adaptada da ref. 82

Ao contrário do exemplo dos alcaloides da vinca, os taxanos interagem preferencialmente com a tubulina polimerizada, ao invés de interagirem com os heterodímeros de tubulina, e acabam por estabilizar os microtúbulos, impedindo a despolimerização. A ligação ocorre na subunidade $\beta$ com estequiometria de 1:1, sendo esse processo específico e reversível (Figura 6). ${ }^{18}$

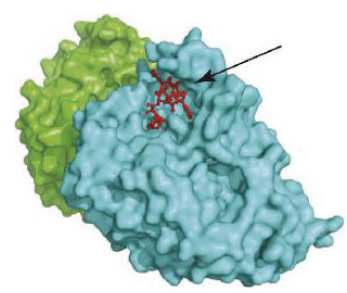

Figura 6. Representação estrutural da $\alpha$-tubulina (verde) e $\beta$-tubulina (azul) ligada ao paclitaxel (vermelho). Reproduzido da ref. 18

\section{Outros agentes anticancerígenos derivados de plantas em desenvolvimento}

Recentemente, o número de moléculas alvo usadas para o desenvolvimento de novas opções de tratamento cresceu consideravelmente; uma substância encontrada em plantas e que apresenta atividade antimitótica é a colchicina, isolada de Colchicum autumnale L. (Colchicaceae). Esta é usada clinicamente no tratamento da gota, mas até o momento nenhum uso significativo em terapias anticancerígenas foi establecido, devido à toxicidade apresentada. Esse composto não se liga diretamente à extremidade final do microtúbulo, e sim às tubulinas livres e, consequentemente, há a formação de complexos tubulina-colchicina, que então se copolimerizam, resultando em microtúbulos com inúmeras moléculas de tubulina alternadas com moléculas de colchicina (Figura 3b). Obviamente esse fato interfere na dinâmica normal dos microtúbulos e acaba por reduzir a despolimerização dos mesmos. ${ }^{86}$ Derivados semissintéticos têm sido avaliados visando contornar os efeitos tóxicos observados da colchicina.

Outras moléculas alvo são as proteínas transdutoras de sinais, as quinases, que regulam processos malignos em células. Um exemplo pode ser a emodina, ou 1,3,8-tri-hidróxi-6-metilantraquinona (24), isolada do ruibarbo, Rheum palmatum L. (Polygonaceae), que inibe a caseína quinase-2 (CK2). ${ }^{18,87}$ CK2 é uma enzima relacionada com processos de regulação de desenvolvimento, incluindo o ciclo celular e a diferenciação. A creatinoquinase isoenzima $\mathrm{MB}$ (CKMB), utilizada como marcador de infarto do miocárdio, também é referida como CK-2.

Emodina é uma antraquinona com reconhecida ação vasorrelaxante, hepatoprotetora, imunossupressora e principalmente laxante, ${ }^{88}$ porém tal composto tem mostrado bons resultados em testes iniciais para terapias anti-carcinogênicas, inibindo a proliferação celular, induzindo a apoptose e prevenindo metástases. ${ }^{89}$ 

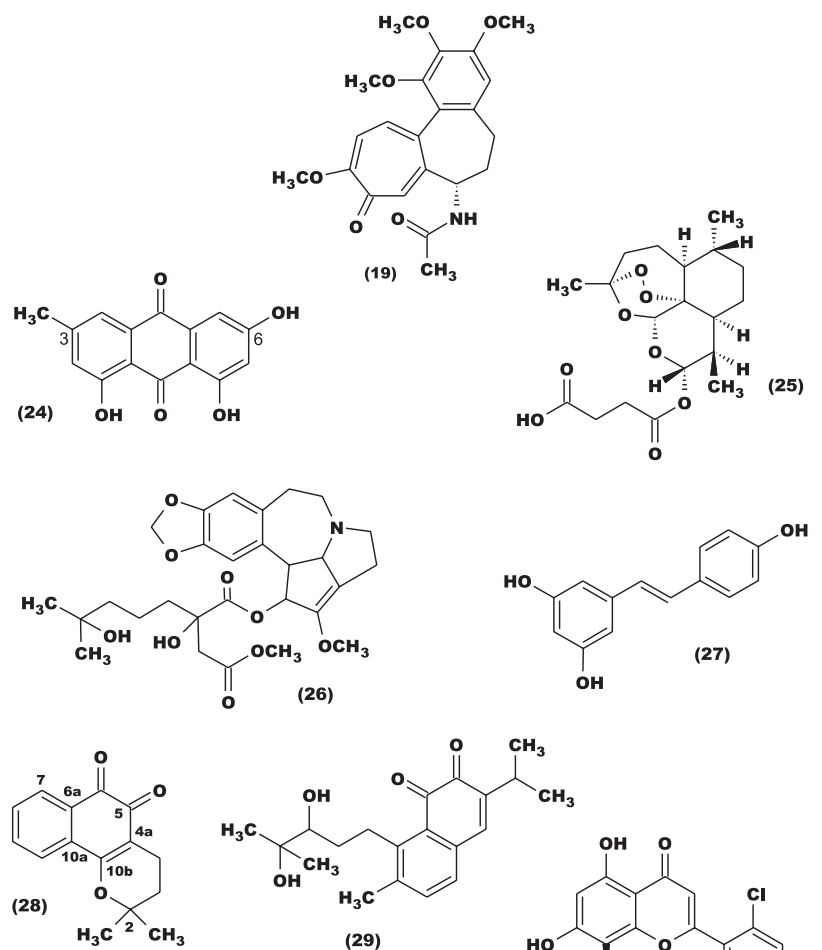<smiles>Cc1ccc2c(c1CCC(O)C(C)(C)O)C(=O)C(=O)C(C(C)C)=C2</smiles><smiles>CN1CC[C@H](c2c(O)cc(O)c3c(=O)cc(-c4ccccc4Cl)oc23)[C@H](O)C1</smiles><smiles>COc1ccc(/C=C\c2cc(OC)c(OC)c(OC)c2)cc1O</smiles>

(29)<smiles>COc1cc(C/C(C)=C/C=C/C(OC)[C@]2(O)C[C@@H]([C@@H](C)[C@H]3O[C@]3(C)[C@H](CC(=O)N(C)c3cc(C(C)(C)C)cc(OC)c3Cl)OC(=O)[C@H](C)N(C)C(C)=O)OC(=O)N2)cc(OC)c1</smiles><smiles>Cc1c2cnccc2c(C)c2c1[nH]c1ccccc12</smiles><smiles>CN(C)Cc1ccccc1</smiles>

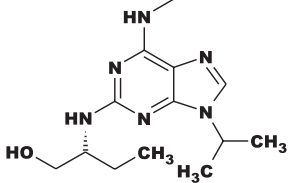
(33)

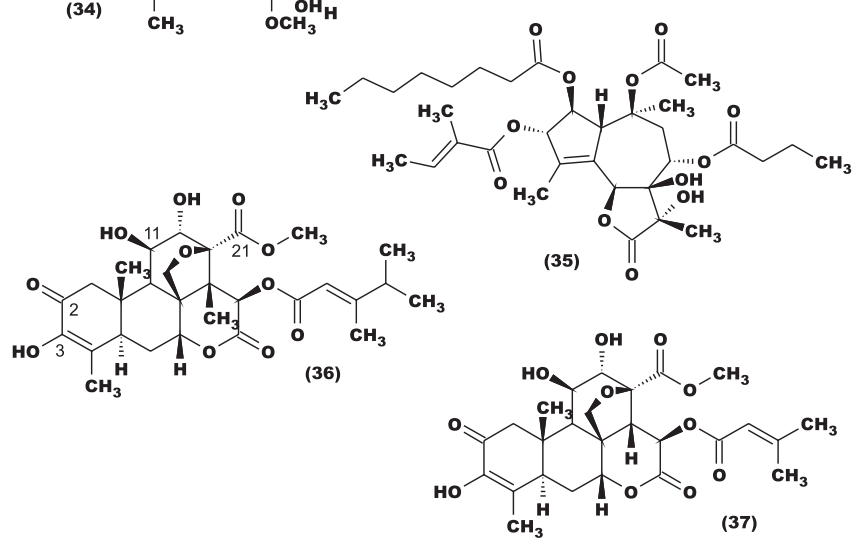

Figura 7. Estruturas químicas de potenciais agentes anticancerígenos derivados de plantas

Estudos recentes mostram que a emodina pode induzir apoptose em diversos tipos de células cancerígenas humanas como as que pertencem ao pulmão, fígado, ovário e sangue. ${ }^{89} \mathrm{O}$ medicamento gencitabina associado com a emodina apresenta efeito sinérgico na inibição da proliferação de células cancerígenas pancreáticas, aumen- tando a ação da primeira como antitumoral in vivo e in vitro ${ }^{87}$ Além disso, foi comprovado que as antraquinonas do ruibarbo que possuem substituintes polares em C- 6 ou C-3 desempenham importante papel na inibição da angiogênese, como observado para a emodina. ${ }^{90}$

$\mathrm{O}$ artesunato (25), 1,2- $\alpha$-succinato da di-hidro-artemisinina, é o derivado semissintético da artemisinina que é extraída da planta medicinal chinesa, Artemisia annua L. (Asteraceae), cuja aplicação como antimalárica já é bem estabelecida. Estudos recentes mostram que o artesunato pode ser uma boa alternativa para o tratamento de alguns tipos de câncer, pelo mecanismo antiangiogênico. A atividade contra leucemia mieloide crônica in vitro e in vivo aliada à baixa toxicidade mostra que essa substância representa um quimioterápico antileucêmico promissor, ${ }^{91}$ em concentrações que variam de 0,75-100 $\mu \mathrm{g} / \mathrm{mL} .^{92}$. É importante salientar que o artesunato não é transportado por P-glicoproteínas, portanto não está envolvido em resistência a multidrogas. ${ }^{18}$

Em linhagens de células cancerígenas pancreáticas, o artesunato induz apoptose e este efeito depende do estágio de diferenciação, sendo mais efetivo contra células pouco diferenciadas. Assim, este potencializa o efeito da gencitabina no controle do câncer pancreático. ${ }^{93}$

O componente natural conhecido como homo-harrigtonina (26) foi primeiro isolado em 1963 e é encontrado em cascas de várias espécies do gênero Cephalotaxus (Cephalotaxaceae), incluindo $C$. harringtonia $\mathrm{K}$. Koch, $C$. haianensis e $C$. qinensis, sendo todos arbustos utilizados na medicina tradicional chinesa (MTC) para tratamentos de câncer. A homo-harrigtonina é ativa contra vários tipos de tumor, principalmente leucemias e câncer de mama, e atua inibindo a síntese proteica ligando-se à subunidade $60 \mathrm{~S}$ nos ribossomos, ${ }^{94}$ levando à apoptose. Um inconveniente é que a atividade anticancerígena pode ser diminuída por P-gp, porém derivados estão sendo estudados para tentar contornar esse fato. ${ }^{18}$ Atualmente é possível semissintetizar o componente a partir do metabólito cefalotaxina extraído de folhas de Cephalotaxus spp., com rendimento setenta vezes maior e, portanto, com menor quantidade de material vegetal. ${ }^{95}$

O 3,5,4'-tri-hidróxi-trans-estilbeno, ou resveratrol (27), é uma fitoalexina produzida por vários vegetais que afeta os três estágios de carcinogênese, conhecidos como iniciação, promoção e progressão do tumor, além de supressão de angiogênese e metástase. Cascas de uvas, Vitis vinifera L. (Vitaceae), contêm cerca de 50 a $100 \mu \mathrm{g}$ de resveratrol por grama de peso seco, o que contribui para a alta concentração relativa desse componente em vinhos tintos e sucos de uva. ${ }^{96}$ Como agente quimiopreventivo e quimioterapêutico, o resveratrol atua na inibição da carcinogênese mamária ${ }^{97} \mathrm{e}$, aparentemente, age por diferentes mecanismos que não estão totalmente elucidados. O efeito de inibição do crescimento de células cancerosas, exercido por essa substância, parece estar relacionado com ação nas enzimas DNA polimerase e ribonucleotídeo redutase, que estão envolvidas na profliferação celular. ${ }^{98} \mathrm{O}$ efeito antiproliferativo em células U937 (leucemia humana) ocorre na fase $\mathrm{S}$ do ciclo celular. São atribuídas ainda as atividades de indutor de apoptose ${ }^{99}$ de células danificadas, antiangiogênico e antimetastático. ${ }^{100}$ Devido a sua estrutura fenólica, possui comprovada atividade antioxidante, por inibição da formação de radicais livres, o que justifica a redução do stress oxidativo e mutagênico. ${ }^{101}$ Vários derivados análogos do resveratrol estão sendo sintetizados e testados para aumentar a potência como antitumoral e os primeiros resultados são promissores. ${ }^{102}$

$\beta$-lapachona (28), ou 3,4-di-hidro-2,2-dimetil-2H-naftol[1,2-b] piran-5,6-diona, é uma orto-naftoquinona lipofílica, derivada do lapachol, componente natural obtido da árvore nativa da América do Sul, ipê roxo, Tabebuia avellanedae Lorentz ex Griseb (Bignoniaceae). Vários efeitos farmacológicos são atribuídos a esse componente, tais como antifúngico, antibacteriano, antitripanossoma e antitumoral. Esta última atividade é devida à ligação por interação direta com as enzimas DNA 
topoisomerase I e II. ${ }^{103}$ A $\beta$-lapachona mostrou-se ativa contra vários tipos de câncer ${ }^{104} \mathrm{e}$, em associação com taxol, é altamente efetiva contra câncer de próstata e de ovário. ${ }^{105} \mathrm{O}$ grande inconveniente da $\beta$-lapachona é a elevada toxicidade; com isso, estão sendo testados vários análogos sintéticos, nos quais o anel o-quinona é mantido intacto. ${ }^{106}$

Derivado modificado de diterpenoquinona isolada de planta utilizada na MTC, Salvia prionitis Hance (Labiatae), a salvicina (29) possui potente atividade antitumoral in vitro e in vivo, e largo espectro de atividades anti-MDR e antimetastática. ${ }^{107}$ A salvicina atua induzindo a quebra das duas fitas do DNA por facilitação da atividade da TOP2 e subsequente inibição da religação, o que está relacionado com a potente capacidade de inibir o crescimento de tumores. Em células cancerosas humanas a salvicina induz danos a genes específicos do DNA, levando esta à apoptose.

Sabe-se que o modo de ação desse composto na TOP2 é diferente dos outros já citados anteriormente, ${ }^{108}$ pois este se liga ao complexo ATPase promovendo a ligação da TOP2 ao DNA que inibe a religação mediada pela TOP2 e hidrólise de ATP. ${ }^{109}$ A salvicina promove depleção intracelular de glutationa que resulta em geração de $\mathrm{H}_{2} \mathrm{O}_{2}$ e inibição da TOP2 e como resultado tem-se a quebra da dupla fita e apoptose. ${ }^{110}$

Flavopiridol, $N$-metil-piperidinil-clorofenil flavona (30) é totalmente sintético, mas o esqueleto base desse novo flavonoide é o produto natural, rohitukina, isolado de Dsoxylum binectarigerum Hook. F. (Meliaceae), sendo responsável pelas atividades anti-inflamatória e imunomoduladora. Flavopiridol foi um dos mais de 100 análogos sintetizados durante estudos de relação estrutura-atividade e mostrou-se ativo na tirosina quinase e inibidor de crescimento de linhagens de células cancerosas de mama e pulmão. ${ }^{111}$ Tal componente mostrou ser cem vezes mais seletivo para quinases ciclina-depedentes (Cdks), sendo o primeiro identificado pelo NCI como possível agente antitumoral $^{112} \mathrm{e}$, consequentemente, foi comprovado como inibidor específico de Cdk. ${ }^{113}$

Cdks estão desreguladas em células cancerosas, o que contribui para a resistência do tumor aos agentes citotóxicos, incluindo radiação. Portanto, inibidores destas Cdks aumentam a eficácia de quimioterápicos e tratamentos por radiação em inúmeros tipos de células tumorais. ${ }^{114}$ Apesar de resultados pré-clínicos promissores, a atividade clínica observada para o flavopiridol em tipos variados de câncer tem deixado a desejar. ${ }^{115}$

As combretastatinas correspondem à classe de estilbenos que contém dois anéis fenílicos não coplanares ligados por C-C com várias metoxilas no sistema e atuam como agentes antiangiogênicos. Essas substâncias foram isoladas da casca de uma árvore sul africana, conhecida como Combretum caffrum (Eckl. \& Zeyh.) Kuntze (Combretaceae), na década de 1970, como parte do programa randômico desenvolvido pelo NCI. Na África, essa espécie é utilizada pela população para tratar diversas enfermidades como hepatite, malária e câncer. ${ }^{112} \mathrm{O}$ análogo solúvel em água, combretastatina A4 (CA4) (31), não é reconhecido por P-gp e tem se mostrado bastante promissor nos ensaios clínicos preliminares. Vários outros análogos trimetóxi-aril estão em fase de desenvolvimento, inclusive para tentar evitar a isomerização dos anéis fenílicos, visto que somente a configuração cis é ativa. ${ }^{116}$ Além dessa característica, são necessários outros requisitos estruturais que incluem a unidade tri-metóxi-fenil, o grupo p-metóxi-fenil, a presença de anéis aromáticos e uma distancia de 4-5 ̊̊ entre os anéis fenílicos. ${ }^{117}$

Devido à semelhança estrutural, a CA4 atua também se ligando no mesmo sítio da colchicina, na $\beta$-tubulina, inibindo a polimerização da tubulina. ${ }^{118}$ Os efeitos colaterais mais comuns observados com o uso da CA4 incluem os cardiovasculares, hiper e hipotensão, linfopenia e dor. Porém, não apresenta os efeitos tradicionais de outros agentes citotóxicos, tais como mielossupressão e alopecia.
A elipticina ou 5,11-dimetil-6H-pirido(4,3-b)carbazol (32) é um alcaloide que apresenta em sua estrutura química a fração carbazólica ligada a anel piridínico e, juntamente com seus derivados mais solúveis, exibem considerável atividade antitumoral. ${ }^{119}$ A elipticina é encontrada em espécies de Apocyanaceae, tendo sido em 1959 o primeiro relato de seu isolamento das folhas de Ochrosia elliptica Labill. As elipticinas podem interagir com o DNA por intercalação ${ }^{120}$ ou inibição da TOP2, além disso, podem interromper o ciclo celular por regulação da expressão de algumas quinases, tais como ciclina B1 e Cdc2. Além disso, podem agir através da fosforilação dessa última ciclina, induzindo a apoptose e geração de radicais livres citotóxicos. ${ }^{121}$ Estudos demonstram que a elipticina e derivados, principalmente eliptinium, são particularmente ativos no câncer de mama. ${ }^{122}$ Entretanto, apresentam como efeito adverso xerostomia, associada com perda de peso e toxicidade renal. ${ }^{123}$

Outro agente sintético baseado em produto natural é a $(\mathrm{R})$ - roscovitina (33), derivada da olomucina, substância originalmente isolada dos cotilédones de Raphanus sativus L. (Brassicaceae). A olomucina demonstra atividade inibitória das proteínas quinases (Cdk) e modificações químicas resultaram no desenvolvimento do derivado muito mais potente, a roscovitina. ${ }^{12}$ As indicações terapêuticas da roscovitina que estão em fases clínicas de análise são câncer de mama e glomerulonefrite. Estudos mostram que o provável mecanismo de ação em casos de câncer de mama está relacionado com a inibição de Cdks, sendo principalmente ativa contra Cdk1, Cdk2 e Cdk5, ${ }^{124}$ que induz a interrupção do ciclo celular nas fases G1 e G2. ${ }^{125}$ A roscovitina também apresentou atividade de inibição da síntese de RNA em células humanas, provavelmente por outro mecanismo que não seja a inibição de Cdk. ${ }^{126}$ Além disso, demonstra boa atividade em combinação com irradiação no caso de câncer de mama e com inibidores de farnesiltransferase para várias linhagens de células. ${ }^{127}$ Destaca-se que o uso da roscovitina associado com resveratrol potencializa o efeito deste último. ${ }^{128}$

A maytansina (34) foi isolada no início da década de 1970 da planta etíope Maytenus serrata (Hochst. Ex A. Rich.) Wilczek (Celastraceae). É digno de nota que essa planta foi também coletada de forma randômica para o mesmo programa do NCI que resultou na descoberta do taxol. ${ }^{112}$ A maytansina e seus derivados fazem parte de uma classe de produtos naturais conhecidos como antibióticos benzoansamacrolídeos, ou maytansinoides, que possuem apreciável atividade antimitótica por se ligarem à tubulina e inibirem sua polimerização. Atuam pelo mesmo mecanismo dos alcaloides da vinca, ${ }^{129}$ chegando alguns maytansinoides a serem de 20 a 100 vezes mais potentes que a vincristina in vitro. ${ }^{130}$ Apesar do baixo rendimento, 2 x $10^{-5} \%$ em peso de planta seca, a alta potência da maytansina permitiu a produção de quantidade suficiente para o desenvolvimento dos testes pré-clínicos. ${ }^{112}$ Mesmo sendo muito ativa nesses testes, os resultados não foram repetidos nos testes clínicos e observou-se uma estreita janela terapêutica para essa classe, sendo os estudos interrompidos no início da década de 1980 . Atualmente, alguns derivados da maytansina encontram-se em fase de desenvolvimento, inclusive com estudos clínicos em vários tipos de câncer, de modo a contornar os problemas apresentados. ${ }^{131}$

Maytansinoides agem também como anticorpos monoclonais tumor-reativo, que são moléculas que se ligam com grande afinidade aos receptores expressos na superfície de células cancerosas. ${ }^{131}$

Isolada da raiz de Thapsia garganica $\mathrm{L}$. (Apiaceae), coletada na ilha de Ibiza, a tapsigargina (TG) (35) é um sesquiterpeno lactônico e representa mais um exemplo de grande interesse na busca de novos anticancerígenos. A TG induz apoptose em células cancerosas quiescentes e proliferativas de próstata e, apesar de não apresentar seletividade para essas células, nos testes clínicos tem sido associada a um pequeno peptídeo carreador, de modo a produzir um pró-fármaco 
hidrossolúvel, que é ativado por antígenos específicos de próstata (PSA). ${ }^{112}$ A TG é também inibidora específica da bomba $\mathrm{Ca}^{2+} / \mathrm{ATPase}$ presente no retículo endoplasmático, com isso depleta $\mathrm{Ca}^{2+}$ intracelular, podendo estar associada ao aumento de $\mathrm{Ca}^{2+}$ extracelular em outras células. Portanto, a capacidade de perturbações nos níveis de $\mathrm{Ca}^{2+}$ celular, associado com a apoptose, faz da TG uma promissora molécula citotóxica. ${ }^{132}$ Além do aumento de $\mathrm{Ca}^{2+}$ celular, TG pode aumentar a quantidade de óxido nítrico (NO) citosólico, que também está associado com a apoptose dessa célula. ${ }^{133}$

Outro exemplo de fármaco remoto da mesma era do taxol e camptotecina, com capacidade de lançamento no mercado é a bruceantina (36), o quassinoide que foi primeiro isolado da árvore etíope Brucea antidysenterica J. F. Mill. (Simaroubaceae), que é utilizada pela população local no tratamento de "câncer". ${ }^{112}$ Assim como outros casos já citados, a bruceantina também apresentou ótimos resultados préclínicos em grande variedade de tumores, porém não obteve resultados satisfatórios nos ensaios clínicos. Recentemente foram observadas atividades significantes em linhagens de células de leucemia, linfoma e mieloma, assim como em modelos animais com estágios avançados da doença, o que acabou por renovar o interesse por tal molécula. Essa atividade está relacionada com a regulação de uma oncoproteína chave, c-MYC. ${ }^{134}$ Entre os efeitos colaterais apresentados pela bruceantina, destacam-se hipotensão, náusea e vômitos, bem como a moderada toxicidade hematológica, por exemplo, a trombocitopenia. O principal mecanismo responsável pela atividade antineoplásica a nível molecular dessa substância é atribuído à inibição da síntese proteica, via interferência na peptidiltransferase, que evita a formação da ligação peptídica. ${ }^{13 .}$

Algumas estruturas congêneres, como o brusatol (37) que foi obtido de $B$. sumatrana Roxb e $B$. javanica Merr., mostram também potentes efeitos antitumorais. Estudos de relação estrutura-atividade sugerem que para que essas moléculas apresentem boa atividade, necessitam ter um oxigênio carbonílico enona ou enólico em C-2, um grupo C-11- $\beta$-hidroxil. Destaca-se que o tamanho da cadeia carbônica do éster alcóxi na cadeia lateral em C-21, assim como o oxigênio em $\mathrm{C}-3$, praticamente não influenciam na atividade antitumoral. ${ }^{136}$

\section{CONSIDERAÇÕES FINAIS}

O câncer representa uma enfermidade cada vez mais comum em todo o mundo e a busca por moléculas cada vez mais potentes e menos tóxicas é constante, tendo como grande fornecedor de moléculas a natureza. As plantas são consideradas fonte nobre de moléculas para o tratamento de várias formas de câncer e, mesmo que a molécula isolada do vegetal não possa ser usada diretamente como medicamento, pode servir de modelo para síntese ou para gerar um pró-fármaco para o desenvolvimento de novos agentes.

Com o avanço de novas tecnologias e melhor compreensão dos mecanismos do câncer e de ação alguns fármacos, muitas moléculas que foram descartadas anteriormente por não apresentarem atividade satisfatória em testes clínicos, ou elevada toxicidade, estão sendo novamente investigadas e/ou modificadas quimicamente na tentativa de obtenção de novos medicamentos. Ilustram esse fato os importantes medicamentos anticancerígenos existentes atualmente no mercado que tiveram o início dos testes clínicos marcados por falta de atividade, elevada toxicidade ou baixa solubilidade, como taxol, camptotecina, derivados da podofilotoxina, e os chamados alcaloides da vinca.

Distintos mecanismos de ação são encontrados nos antineoplásicos derivados de plantas, tais como interação com DNA, inibição enzimática e interação com outras proteínas. Todos os mecanismos visam à interrupção do ciclo de células cancerosas, tendo como característica essencial o máximo de distinção entre estas com as células normais.
Outro entrave possível para o desenvolvimento de medicamentos anticancerígenos a partir de plantas é a pequena concentração dessas moléculas ativas que, a depender do caso, pode ser contornada pelo aumento da potência desses componentes, através da produção de derivados por meio de reações de semissíntese ou mesmo por técnicas de cultura de tecidos vegetais que garantam a maior produção da molécula de interesse.

A análise dos resultados obtidos pelos métodos de triagem utilizados até 1985 revela que a maioria dos fármacos desenvolvidos são úteis em tumores de crescimento rápido, como as leucemias e linfomas. Realmente o sucesso da quimioterapia é maior quando os tumores pertencem ao sistema hematopoiético, enquanto que para os tumores sólidos as alternativas são muito escassas.

Considerando que menos de $10 \%$ das espécies de plantas tiveram algum tipo de estudo fitoquímico ou de atividades biológicas, acreditase que muitos medicamentos derivados de plantas ainda estejam por ser descobertos, incluindo os anticancerígenos. Porém, não se trata de uma tarefa simples, visto que de cada 5 mil estruturas químicas testadas, uma se torna medicamento.

\section{AGRADECIMENTOS}

Ao CNPq, à CAPES e FAPESB pelos auxílios e bolsas.

\section{REFERÊNCIAS}

1. Newman, D. J.; Cragg, G. M.; Snader, K. M.; Nat. Prod. Rep. 2000, 17, 215.

2. Chin, Y. W.; Balunas, M. J.; Chai, H. B.; Kinghorn, A. D.; The AAPS J. 2006, 8, 239.

3. Newman, D. J.; Cragg, G. M.; Snader, K. M.; J. Nat. Prod. 2003, 66, 1022.

4. Balunas, M. J.; Kinghorn, A. D.; Life Sci. 2005, 78, 431; Santos, E. O.; Lima, L. S.; David, J. M., Martins, L. C.; Guedes, M. L. S.; David, J.P.; Nat. Prod. Res. 2010, 16, doi 10.1080/14786410902809500.

5. Thayer, A.; Chem. Eng. News 2003, 81, 6.

6. Oberlies, N. H.; Kroll, D. J.; J. Nat. Prod. 2004, 67, 129.

7. Altmann, K. H.; Gertsch, J.; Nat. Prod. Rep. 2007, 24, 327.

8. Guerra, M. R.; Gallo, C. V. M.; Azevedo, G.; Mendonça, S.; Rev. Bras. Cancerol. 2005, 51, 3.

9. http://www.who.int/mediacentre/factsheets/fs297/en/, acessada Janeiro 2008.

10. Almeida, V. L.; Leitão, A.; Reina, L. C. B.; Montanari, C. A.; Donnici, C. L.; Lopez, M. T. P.; Quim. Nova 2005, 28, 118.

11. http://info.cancerresearchuk.org/cancerstats/incidence/age/, acessada Janeiro 2009.

12. http://www.cancer.gov, acessada Janeiro 2009.

13. http://www.inca.gov.br, acessada Março 2009.

14. Carvalho, J. E.; Multiciência: construindo a história dos produtos naturais 2006, 7, 1.

15. Nobili, S.; Lippi, D.; Witort, E.; Donnini, M.; Bausi, L.; Mini, E.; Capaccioli, S.; Pharmacol. Res. 2009, 59, 365.

16. Yang, C. S.; Lambert, J. D.; Ju, J.; Lu, G.; Sang, S.; Toxicol. Appl. Pharmacol. 2007, 224, 265.

17. Mann, J.; Nat. Rev. Cancer. 2002, 2, 143.

18. Efferth, T.; Li, P. C. H.; Konkimalla, V. S. B.; Kaina, B.; Trends Mol. Med. 2007, 13, 353.

19. Pommier, Y.; Nat. Rev. Cancer. 2006, 6, 789.

20. Chabne, B. A.; Roberts Jr, T. G.; Nat. Rev. Cancer. 2005, 5, 65.

21. Kweekel, D.; Guchelaar, H. J.; Gelderblom, H.; Cancer Treat. Rev. 2008, 34, 656 .

22. Teicher, B. A.; Biochem. Pharmacol. 2008, 75, 1262.

23. Boisse, T.; Gavara, L.; Hénichart, J. P.; Rigo, B.; Gautret, P.; Tetrahedron 2009, 65, 2455. 
24. Takagi, K.; Dexheimer, T. S.; Rendon, C.; Sordet, O.; Agama, K.; Lavielle, G.; Pierré, A.; Bates, S. E.; Pommier, Y.; Mol. Cancer Ther. 2007, 6, 3229.

25. Jong, F. A.; Jonge, M. J. A.; Verweij, J.; Mathijssen, R. H. J.; Cancer Lett. 2006, 234, 90.

26. Choi, D. H.; Ha, J. S.; Lee, W. H.; Song, J. K.; Kim, G. Y.; Park, J. H.; Cha, H. J.; Lee, B. J.; Park, J. W.; FEBS Lett. 2007, 581, 1649.

27. Dadashzah, S.; Vali, A. M.; Rezaie, M.; Int. J. Pharm. 2008, 353, 251.

28. Zarougoulidis, K.; Mylonaki, E.; Kakavelas, P.; Zarougoulidis, P.; Tsiouda, T.; Rapti, E.; Lithoxoupoulou, H.; Zarougoulidou, V.; Kontakiotis, T.; Lung Cancer 2009, 66, 226.

29. Mancuso, A.; Calabrò, F.; Sternberg, C. N.; Crit. Rev. Onco. Hemat. 2006, 58, 231.

30. Chua, Y. J.; Cunningham, D.; Best Pract. Res. Cl. Ga. 2006, $20,327$.

31. Braybrook, J. P.; Ranson, M.; Manegold, C.; Mattson, K.; Thatcher, N.; Cheverton, P.; Sekiguchi, M.; Suzuki, M.; Oyama, R.; Talbot, D. C.; Lung Cancer 2003, 41, 215.

32. Clamp, A.; Adams, M.; Atksion, R.; Boven, E.; Calvert, A. H.; Cervantes, A.; Ganesan, T.; Lotz, J.; Vasey, P.; Cheverton, P.; Jayson, G. C.; Gynecol. Oncol. 2004, 95, 114.

33. Reichardt, P.; Nielsen, O. S.; Bauer, S.; Hartmann, J. T.; Schoffski, P.; Christensen, T. B.; Pink, D.; Daugaard, S.; Marreaud, S.; Glabbeke, M. V.; Blay, J. Y.; Eur. J. Cancer. 2007, 43, 1017.

34. Haglof, K. J.; Popa, E.; Hochster, H. S.; Update Cancer Therap. 2006, $1,117$.

35. Seide, M. V.; Muggia, F.; Astrow, A.; Matulonis, U.; Campos, S.; Roche, M.; Sivret, J.; Rusk, J.; Barret, E.; Gynecol. Oncol. 2004, 93, 229.

36. Duffaud, F.; Borner, M.; Chollet, P.; Vermorken, J. B.; Bloch, J.; Degardin, M.; Rolland, F.; Dittrich, C.; Baron, B.; Lacombe, D.; Fumoleou, P.; Eur. J. Cancer. 2004, 40, 2748.

37. Larsen, A. K.; Escargueil, A. E.; Skaladanowski, A.; Pharmacol. Ther. 2003, 99, 167.

38. Felix, C. A.; Kolaris, C. P.; Osheroff, N.; DNA Repair. 2006, 5, 1093.

39. Uesaka, T.; Shono, T; Kuga, D; Suzuki, S. O.; Niiro, H.; Miyamoto, K.; Matsumoto, K.; Mizoguchi, M.; Ohta, M.; Iwaki, T.; Sasaki, T.; J. Neurooncol. 2007, 84, 119.

40. Canel C.; Moraes, R. M.; Dayan, F. E.; Ferreira, D.; Phytochemistry 2000, 54, 115.

41. Imbert, T.; Biochimie 1998, 80, 207.

42. Joel, S.; Cancer Treat. Rev. 1996, 22, 179.

43. Hande, K. R.; Update Cancer Therap. 2006, 1, 3.

44. Muggia, F. M.; Cancer Chemother. Pharmacol. 1994, 34, S127.

45. Jordan, M. A.; Wilson, L.; Nat. Rev. Cancer. 2004, 4, 253.

46. Teckchandani, A. M.; Birukova, A. A.; Tar, K.; Verin, A. D.; Tsygankov, A. Y.; Exp. Cell Res. 2005, 306, 114.

47. McCrogan, B. T.; Gilmartin, B.; Carney, D.; McCann, A.; Biochim. Biophys. Acta 2008, 1785, 96.

48. Cosset, J. M.; Fermé, C.; Noordijk, E. M.; Bubray, B. M.; Thirion, P.; Amar, M. H.; Semin. Rad. Oncol. 1996, 6, 185.

49. Beek, R. D.; Eibrink, M. M. H.; Cammel, F. G. H.; Bos, C.; Pal, H. J. H.; Krenning, E. P.; Rijke, Y. B.; Pieters, R.; Schrama, S. M. P. F. K.; J. Clin. Endocrinol. Metab. 2009, 94, 1904

50. Barzdo, M.; Zydek, L.; Kazmirska, A. S.; Zgoda, M.; Machała, W.; Berent, J.; Pharm. World Sci. 2009, 31, 362.

51. Steurer, G.; Kuzmits, R.; Pavelka, M.; Sinzinger, H.; Fritz, E.; Ludwig, H.; Cancer 1989, 1, 51.

52. Ozgen, U.; Turkoz, Y.; Stout, M.; Ozugurlu, F.; Pelik, F.; Bulut, Y.; Aslan, M.; Ravindranath, Y.; Savasan, S.; Leukemia Res. 2003, 27, 1109.

53. Groniger, E.; Boer, T. M.; Koopmans, P.; Uges, D.; Sluiter, W.; Veerman, A.; Kamps, W.; Graaf, S.; Eur. J. Cancer. 2005, 41, 98.

54. Mohammad, R. M.; Diwakaran, H.; Maki, A.; Emara, M.; Pettit, G.; Redman, B.; Katib, A. A.; Leukemia Res. 1995, 19, 667.

55. Marcaigh, A. S. O.; Betcher, D. L.; J. Pediat. Oncol. Nurs. 1995, 12, 140.
56. Aapro, M. S.; Conte, P.; González, E. E.; Lenoir, V. T.; Drugs 2007, 67, 657.

57. Loo, W. T. Y.; Hasano, H.; Chow, L. W. C.; Biomed. Pharmacother. 2007, 61, 596.

58. Chadegani, A. R.; Chamani, E.; Hajihassan, Z.; Moll. Cell. Pharmacol. 2009, 613, 34.

59. Vats, T. S.; Mehta, P.; Trueworthy, R. C.; Smith, S. D.; Klopovich, P.; Cancer 1981, 47, 2789.

60. Ishikawa, H.; Colby, D. A.; Seto, S.; Va, P.; Tam, A.; Kakei, H.; Rayl, T. J.; Hwang, I.; Boger, D. L.; J. Am. Chem. Soc. 2009, 131, 4904.

61. Li, G. Y.; Yu, X. M.; Zhang, H. W.; Zhang, B.; Wang, C. B.; Xin, Y. C.; Yang, C. Z.; Zhou, R. X.; Wang, L. X.; Compl. Ther. Med. 2009, 17, 51.

62. Thomas, M.; Rube, C.; Hoffknecths, P.; Macha, H. N.; Freitag, L.; Linder, A.; Wilich, N.; Hamm, M.; Sybretch, G. W.; Ukena, D.; Deppermann, K. M.; Drodge, C.; Riesenbeck, D.; Heinecke, A.; Sauerland, C.; Junker, K.; Berdei, W. E.; Semik, M.; Lancet Oncol. 2008, 9, 636.

63. Gandara, D. R.; Kawaguchi, T.; Crowley, J.; Moon, J.; Furuse, K.; Kawahara, M.; Teramukai, S.; Ohe, Y.; Kubota, K.; Williamson, S. K.; Gautschi, O.; Lenz, H. J.; Mcleod, H. L.; Nara, P. N. J.; Coltman, C. A. J.; Fukuoka, M.; Saijo, N.; Fukushima, M.; Mack, P. C.; J. Clin. Oncol. 2009, 27, 3540.

64. Kalbakis, K.; Pappas, P.; Kouroussis, C.; Vamvakas, L.; Kalykaki, A.; Vardakis, N.; Nikolaidou, M.; Marselos, M.; Georgoulias, V.; Mavroudis, D.; Cancer Chemother. Pharmacol. 2008, 62, 449.

65. Karam, A. K.; Chiang, J. W.; Fung, E.; Nossov, V.; Karlan, B. Y.; Gynecol. Oncol. 2009, 114, 246.

66. Foruya, Y.; Yanagie, H.; Wakahara, T.; Mishina, Y.; Akimoto, H.; Quang, L. M.; Hiroshima, K.; Yasuhara, H.; Cancer Chemother. Pharmacol. 2009, 64, 623 .

67. Ho, T. F.; Peng, Y. T.; Chuang, S. M.; Lin, S. C.; Feng, B. F.; Lu, C. H.; Yu, W. J.; Chang, J. S.; Chang, C. C.; Toxicol. Appl. Pharmacol. 2009, 235, 253.

68. Zhao, L.; Wei, Y. M.; Zhong, X. D.; Liang, Y.; Zhang, X. M.; Li, W.; Li, B. B.; Wang, Y.; Yu, Y.; J. Pharm. Biomed. Anal. 2009, 49, 989.

69. Favareto, A.; Pasello, G.; Magro, C.; Schettino, C.; Gridelli, C.; Crit. Rev. Oncol. Hemat. 2009, 71, 117.

70. Matsumotto, A.; Inoue, A.; Yokoi, S.; Nozumi, K.; Miyazaki, K.; Hosoki, S.; Nagata, M.; Yamaguchi, K.; Int. J. Urol. 2009, 16, 687.

71. Stratton, K.; Chang, S.; BJU International 2009, 104, 449.

72. Chang, Y. H.; Hsu, M. H.; Wang, S. H.; Huang, L. J.; Qian, K.; Natsch, S. L. M.; Haamel, E.; Kuo, S. C.; Lee, K. H.; J. Med. Chem. 2009, 52, 4883.

73. Gidding, C. E. M.; Kellie, S. J.; Kamps, W. A.; Graaf, S. S. N.; Crit. Rev. Oncol. Hemat. 1999, 29, 267.

74. Kuehne, M. E.; Cowen, S. D.; Xu, F.; Borman, L. S.; J. Org. Chem. 2001, 66, 5303

75. Santos, A. R.; Pinheiro, A. C.; Sodero, A. C. R.; Cunha, A. S.; Padilha, M. C.; Sousa, P. M.; Fontes, S. P.; Quim. Nova 2007, 30, 125.

76. Zhang, H. Y.; Tang, X.; Li, H. Y.; Liu, X. L.; Int. J. Pharm. 2008, 348, 70.

77. Graeve, J. D.; Heugen, V. J. C.; Zorza, G.; Fahy, J.; Puozzo, G.; J. Pharm. Biomed. Anal. 2008, 47, 47.

78. Campagnoli, E.; Garassino, I.; Santoro, A.; Vincenzo, F. D.; Zucali, P. A.; Ceresoli, G. L.; Lutman, F. R.; Alloisio, M.; Parra, H. J. S.; Cavina, R.; Invest. New Drugs 2007, 25, 559.

79. Jagetia, G. C.; Adiga, S. K.; Mutat. Res. 1998, 421, 55.

80. Jacquesy, J. C.; J. Fluorine Chem. 2006, 127, 1484.

81. Simoens, C.; Vermorken, J. B.; Korst, A. E. C.; Pauwels, B.; Pooter, C. M. J. D.; Pattyn, G. G. O.; Lambrechts, H. A. J.; Breillout, F.; Lardon, F.; Cancer Chemother. Pharmacol. 2006, 58, 210.

82. Souza, M. V. N.; Quim. Nova 2004, 27, 308.

83. Viegas Jr.; Bolzani, V. S.; Barreiro, E. J.; Quim. Nova 2006, 2, 326. 
84. Chabner, B. A.; Roberts Jr, T. G.; Nat. Rev. Cancer. 2005, 5, 65.

85. Rodrigues, D. G.; Maria, D. A.; Fernandes, D. C.; Valduga, C. J.; Couto, R. D.; Ibanez, O. C. M.; Maranhão, R. C.; Cancer Chemother Pharmacol. 2005, 55, 565.

86. Nguyen, T. L.; Mcgrath, C.; Hermone, A. R.; Burnett, J. C.; Zaharevitz, D. W.; Day, B. W.; Wipf, P.; Hamel, E.; R. Gussio. J. Med. Chem. 2005, $48,6107$.

87. Guo, Q.; Chen, Y.; Zhang, B.; Kang, M.; Xie, Q.; Wu, Y.; Biochem. Pharmacol. 2009, 77, 1674.

88. Srinivas, G.; Babykutty, S.; Sathiadevan, P. P.; Srinivas, P.; Med. Res Rev. 2007, 27, 591.

89. Huang, Q.; Lu, G.; Shen, H. M.; Chung, M. C. M.; Ong, C. N.; Med. Res. Rev. 2007, 27, 609 .

90. He, Z. H.; He, M. F.; Ma, S. C.; But, P. P. H.; J. Ethnopharmacol. 2009 $121,313$.

91. Zhou, H. J.; Wang, W. O.; Wu, G. D.; Lee, J.; Li, A.; Vasc. Pharmacol. 2007, 47, 131 .

92. Rong, H. R.; Jun, Z. H.; Chin. J. Integr. Med. 2008, 14, 312.

93. Youns, M.; Efferth, T.; Reichling, J.; Fellenberg, K.; Bauer, A.; Hoheisel, J. D.; Biochem. Pharmacol. 2009, 78, 273.

94. Gurel, G.; Blaha, G.; Moore, P. B.; Steitz, T. A.; J. Mol. Biol. 2009, 389, 146.

95. Tang, R.; Faussat, A. M.; Majdak, P.; Marzac, C.; Dubrulle, S.; Marjanovic, Z.; Legrand, O.; Marie, J. P.; Mol. Cancer Ther. 2006, 5, 723.

96. Oliveira, A. C.; Valentin, I. B.; Goulart. M. O. F.; Silva, C. A.; Bechara, E. J. H.; Trevisan, M. T. S.; Quim. Nova 2009, 32, 689; Athar, M.; Back, J. H.; Tang, X.; Kim, K. H.; Kopelovich, L.; Bickers, D. R.; Kim, A. L.; Toxicol. Appl. Pharmacol. 2007, 224, 274.

97. Murias, M.; Miksits, M.; Aust, S.; Spatzenegger, M.; Thalhammer, T.; Szekeres, T.; Jaeger, W.; Cancer Lett. 2008, 261, 172.

98. Park, J. W.; Choi, Y. J.; Jang, M. A.; Lee, Y. L.; Jun, D. Y.; Suh, S.; Baek, W. K.; Suh, M. H.; Jinc, I. N.; Kwona, T. K.; Cancer Lett. 2001, 163, 43.

99. Saiko, P.; Szakmary, A.; Jaeger, W.; Szekeres, T.; Mutat. Res. 2008, 658, 68.

100. Kundu, J. K.; Surh, Y. J.; Cancer Lett. 2008, 269, 243.

101. Barreiros, A. L. B. S.; David, J. M.; David, J. P.; Quim. Nova 2006, 29 , 113; Cecchinato, V.; Chiaramonte, R.; Nizzardo, M.; Cristofaro, B.; Basile, A.; Sherbet, G. V.; Comi, P.; Biochem. Pharmacol. 2007, 74, 156.

102. Jeong, S. H.; Jo, W. S.; Song, S.; Suh, H.; Seol, S. Y.; Leem, S. H.; Kwon, T. K.; Yoo, Y. H.; Biochem. Pharmacol. 2009, 77, 1337.

103. Gupta, D.; Podar, K.; Tai, Y. T.; Lin, B.; Hideshima, T.; Akiyama, M.; Leblanc, R.; Catley, L.; Mitsiades, N.; Mitsiades, C.; Chauhan, D.; Munshi, N. C.; Anderson, K. C.; Exp. Hematol. 2002, 30, 711.

104. Krishnan, P.; Bastow, K.; Biochem. Pharmacol. 2000, 60, 1367.

105. Júnior, E. N. S.; Souza, M. C. B. V.; Pinto, A. V.; Pinto, M. C. F. R.; Goulart, M. O. F.; Barros, F. W. A.; Pessoa, C.; Lotufo, L. V. C.; Montenegro, R. C.; Moraes, M. O.; Ferreira, V. F.; Bioorg. Med. Chem. 2007, 15, 7035 .

106. Wei, P.; Zhang, X.; Tu, S.; Yan, S.; Ying, H.; Ouyang, P.; Bioorg. Med. Chem. 2007, 19, 828.

107. Hu, C. X.; Zuo, Z. L.; Xiong, B.; Ma, J. G.; Geng, M. Y.; Lin, L. P.; Jiang, H. L.; Ding, J.; Mol. Pharmacol. 2006, 70, 1593.

108. Thind, T. S.; Agrawal, S. K.; Saxena, A. K.; Arora, S.; Food Chem. Toxicol. 2008, 46, 2922.

109. Meng, L. H.; Ding, J.; Acta Pharmacol. Sin. 2007, 28, 1460.

110. Cai, Y. J.; Lu, J. J.; Zhu, H.; Xie, H.; Muang, M.; Lin, L. P.; Zhang, X. W.; Ding, J.; Free Radical Biol. Med. 2008, 45, 627.
111. Sausville, E. A.; Zaharevitz, D.; Gussio, R.; Meijer, L.; Louarn-Leost, M.; Kunick, C.; Shultz, R.; Lahusen, T.; Headlee, D.; Stinson, S.; Arbuck, S. G.; Senderowicz, A.; Pharmacol. Ther. 1999, 82, 285.

112. Cragg, G. M.; Newman, D. J.; J. Ethnopharmacol. 2005, 100, 72.

113. Grever, M. R.; Lucas, D. M.; Johnson, A. J.; Byrd, J. C.; Best Pract. Res. Cl. Ha. 2007, 20, 545.

114. Hara, T.; Minamisawa, M. O.; Kang, Y.; Cheng, C.; Inoue, T.; Int. J. Radiation Oncology Biol. Phys. 2008, 71, 1485.

115. Byrd, J. C.; Lin, T. S.; Dalton, J. T.; Wu, D.; Phelps, M. A.; Fischer, B.; Moran, M.; Blum, K. A.; Rovin, B.; Brooker-Mceldowney, M.; Broering, S.; Schaaf, L. J.; Johnson, A. J.; Lucas, D. M.; Heerema, N. A.; Lozanski, G.; Young, D. C.; Suarez, J. R.; Colevas, A. D.; Grever, M. R.; Blood J. 2007, 109, 399.

116. Billard, C.; Menasria, F.; Quiney, C.; Faussat, A. M.; Kolb, J. P.; Leukemia Res. 2008, 32, 755.

117. Sriram, M.; Hall, J. J.; Grohmann, N. C.; Strecker, T. E.; Wootton, T.; Franken, A.; Trawick, M. L.; Pinney, K. G.; Bioorg. Med. Chem. 2008, 16,8161 .

118. Lin, H. L.; Chiou, S. H.; Wu, C. W.; Lin, W. B.; Chen, L. H.; Yang, Y. P.; Tsai, M. L.; Uen, Y. H.; Liou, J. P.; Chi, C. W.; J. Pharmacol. Exp. Ther. 2007, 323, 365.

119. Stiborová, M.; Rupertová, M.; Aimová, D.; Ryslavá, H.; Frei, E.; Toxicology 2007, 236, 50.

120. Poljaková, J.; Frei, E.; Gomez, J. E.; Aimová, D.; Eckschlager, T.; Hrabeta, J.; Stiborová, M.; Cancer Lett. 2007, 252, 270.

121. Kuo, Y. C.; Kuo, P. L.; Hsu, Y. L.; Cho, C. Y.; Lin, C. C.; Life Sci. 2006, $78,2550$.

122. Kuo, P. L.; Hsu, Y. L.; Chang, C. H.; Lin, C. C.; Cancer Lett. 2005, 223, 293.

123. Topcu, Z.; J. Clin. Pharm. Ther. 2001, 26, 405.

124. Goodyear, S.; Sharma, M. C.; Exp. Mol. Pathol. 2007, 82, 25.

125. Zhang, F.; Zhang, T.; Jiang, T.; Zhang, R.; Teng, Z. H.; Li, C.; Gu, Z. P.; Mei, Q.; Cancer Lett. 2009, 286, 232.

126. Li, A. Y.; Han, M.; Zheng, B.; Wen, J. K.; FEBS Lett. 2008, 582, 243.

127. Ribas, J.; Boix, J.; Meijer, L.; Exp. Cell Res. 2006, 312, 2394.

128. Komina, O.; Gadek, J. W.; Biochem. Pharmacol. 2008, 76, 1554.

129. Widdison, W. C.; Wilhelm, S. D.; Cavanagh, E. E.; Whiteman, K. R.; Leece, B. A.; Kovtun, Y.; Goldmacher, V. S.; Xie, H.; Steeves, R. M.; Lutz, R. J.; Zhao, R.; Wang, L.; Blatler, W. A.; Chari, R. V. J.; J. Med. Chem. 2006, 49, 4392.

130. Vora, T.; Azambuja, E.; Awada, A.; Piccart, M.; Update Cancer Therap. 2009, 3, 189.

131. Tassone, P.; Gozzini, A.; Goldmacher, V.; Shammas, M. A.; Whiteman, K. R.; Carrasco, D. R.; Li, C.; Allam, C. K.; Venuta, S.; Anderson, K. C.; Munshi, N. C.; Cancer Res. 2004, 64, 4629.

132. Lee, D. I.; Sumbilla, C.; Lee, M.; Natesavelalar, M.; Klein, M. G.; Ross, D. D; Inesi, G.; Hussain, A.; Arch. Biochem. Biophys. 2007, 464, 19.

133. Canová, N. K.; Kmonicková, E.; Martinek, J.; Zidek, Z.; Farghali, H.; Cell Biol. Toxicol. 2007, 23, 337.

134. Cuendet, M.; Christov, K.; Lantvit, D. D.; Deng, Y.; Hedayat, S.; Helson, L.; Mcchesney, J. D.; Pezzuto, J. M.; Clin. Cancer Res. 2004, 10,1170 .

135. Cuendet, M.; Pezzuto, J. M.; J. Nat. Prod. 2004, 67, 269.

136. Hitotsuyanagi, Y.; Kim, I. H.; Hasuda, T.; Yamauchi, Y.; Takeya, K.; Tetrahedron 2006, 62, 4262. 